\title{
Amylase activity in cerical mucus and serum during estrus in normal and repeat breeder cattle
}

\author{
Ashok Kumar, S. Mehrotra, S. S. Dangi, G. Singh, Mahak Singh, A. S. Mahla \\ Division of Animal Reproduction \\ Indian Veterinary Research Institute, I zatnagar - 243122, UP, India \\ Corresponding author: Ashok Kumar, email: drashokkumar39@gmail.com \\ Received: 19-03-2012, Accepted: 04-04-2012, Published Online: 10-05-2012 \\ doi: $10.5455 /$ vetworld.2012.486-488
}

\begin{abstract}
Aim: To compare the amylase activity in the cervical mucus and serum during estrus in normal and repeat breeder cattle and find out importance in fertility.

Materials and methods: Twenty cyclic crossbred cattle were divided into two groups: normal $(\mathrm{n}=10)$ and repeat breeder ( $\mathrm{n}$ $=10$ ). Animals exhibiting spontaneous estrus, were artificially inseminated (AI) twice, as per AM-PM schedule along with simultaneous collection of cervical mucus and blood. Amylase activity was measured by using kits in collected samples.

Result and discussion: Cervical amylase activity was significantly $(\mathrm{p}<0.01)$ higher in normal compared to repeat breeder animals showing important role of cervical amylase in fertility without significant difference in serum profiles between these groups.

Conclusion: Results of study suggest that cervical mucus amylase could be a facilitator of sperm transport and capacitation process in female genital tract leading to acceptable fertility in normal animals.
\end{abstract}

Key words: Amylase, Cervical mucus, Estrus, Repeat breeder cattle, Spermatozoa.

To cite this article: Kumar A, Mehrotra S, Dangi SS, Singh G, Singh M, Mahla AS (2012) Amylase activity in cerical mucus and serum during estrus in normal and repeat breeder cattle, Vet World 5(8): 486-488, doi: 10.5455/vetworld.2012.486-488

\section{I ntroduction}

Assessment of fertility in female by examining genital tract fluids has been receiving considerable attention. The cervix with its unique anatomical and histological structure and secretory function plays an important role in sperm survival and transport to uterine cavity. The primary function of cervical mucus is sperm transport and to act as a mechanical barrier against microbial infection of the uterus. Cervical mucus contain about $92-95 \%$ water along with low molecular weight substances such as electrolytes, carbohydrates, amino acids, lipids and soluble macromolecular compounds such as proteins and polysaccharides dissolved in it [1]. During estrus, the modification of physical and biochemical properties of cervical mucus takes place under influence of sex steroid hormones in order to facilitate the transport of spermatozoa. Cyclic variation in the alkaline phosphatase, amylase and lysozyme in cervical mucus reported by Schumacher [1] and level of peroxidase in the cattle could be used to detect ovulation [2].

Amylase enzyme shows cyclic changes in the cervical mucus of women, rising during the pre- and postovulatory phases and declining around ovulation [3]. The Physical and chemical properties of bovine cervical mucus has been determined in previous studies, but there is a paucity of literature about the activity of enzymes [4]. Therefore, it is logical to determine and compare the activity of enzymes during estrus in cervical mucus in normal and repeat breeder cattle in order to find out abnormalities in cervical mucus and attempt for correction to improve fertility in problematic cases. Thus, the aim of the present study was to determine the amylase activity in the cervical mucus and serum during estrus in normal and repeat breeder cattle.

\section{Materials and Methods}

The present investigation was conducted on twenty clinically healthy crossbred cattle of 4-7 years of age, maintained at the Institute Dairy Farm, Livestock Production and Management Section, Indian Veterinary Research Institute, Izatnagar. Animals were checked for estrus twice daily using teaser bull along with observing behavioural signs of estrus. The selected animals have normal parturition 
Amylase activity in cerical mucus and serum during estrus in normal and repeat breeder cattle

Table-1. Amylase concentration (IU/L) in cervical mucus and serum of normal and repeat breeder cattle (Mean \pm SEM)

\begin{tabular}{lllc}
\hline Groups $(\mathbf{n}=\mathbf{1 0})$ & cervical mucus & serum & Conception rate (\%) \\
\hline I (Normal) & $46.840 \pm 4.597$ & $40.900 \pm 5.061$ & 50 \\
II (Repeat Breeder) & $18.050^{\star \star} \pm 3.590$ & $48.010 \pm 3.646$ & 40 \\
\hline
\end{tabular}

"* Mean differ Significantly $(P<0.01)$ in column

and not have postpartum anestrus and breeding was done after 45 days of voluntary waiting periods. BCS was 4.5-5 (scale 0-8) and the status of genital tract and ovaries was examined by rectal plalpation for proper uterine involution, cystic ovaries and found normal at days 30 postpartum as well as at time of AI. Animals were grouped in two groups: Group I (normal cyclic, $\mathrm{n}=10$ ) were inseminated for less than 3 times after the last calving and Group II (repeat breeder, $n=10$ ) which were inseminated for more than 3 times but failed to conceive. The animals were maintained under isomanagerial conditions with intensive system of feeding. They were housed in a well ventilated brick cemented house with non-slippery floor and offered standard ration having green and dry fodder along with concentrate. Prior approval for experiments was taken from Institutional Animal Ethics Committee as per CPCSEA (Govt. of India) norms.

Cervical mucus and blood samples were collected from mid to late estrus animals i.e. if the animals were detected in estrus during morning, the sampling and AI was done in same evening and if the animals came in heat in the evening then sampling and AI was done in next morning. Cervical mucus samples were collected from animals prior to insemination using AI gun sheath and syringe from cervix with precautions to avoid contamination by proper washing of perineal region with diluted potassium permanganate solution in water followed by cleaning with spirit swab. Cervical mucus was placed into a 10 $\mathrm{ml}$ plastic tube and transported to the laboratory in a refrigerated box $\left(4^{\circ} \mathrm{C}\right)$. Aliquots of 1.5 to $2 \mathrm{ml}$ of cervical mucus were homogenized in a vortex homogenizer and stored at $-20^{\circ} \mathrm{C}$ for measurement of enzymatic activity in future. Blood samples were collected from jugular vein aseptically and serum was separated by centrifugation at $3000 \mathrm{rpm}$ for $15 \mathrm{~min}$ and stored at $-20^{\circ} \mathrm{C}$ until analysis.

Amylase enzyme activity in the cervical mucus and serum samples was assayed by as per kit (Span Diagnostics Ltd. Surat, India) using spectrophotometer. For test sample was taken $0.5 \mathrm{ml}$ of buffered substrate, mixed well and incubated at $37^{\circ} \mathrm{C}$ for $3 \mathrm{~min}$, then added homogenized mucus $(50 \mu \mathrm{l})$ and incubated for $15 \mathrm{~min}$ at $37^{\circ} \mathrm{C}$ followed by addition of purified water $(4.0 \mathrm{ml})$ and working iodine solution $(0.2 \mathrm{ml})$ mixed well and measured optical density $(O \mathrm{D})$ using red filter at $620 \mathrm{~nm}$ wavelength against purified water.

Statistical analysis: The comparison of amylase in the cervical mucus and serum were performed by student's ' $t$ ' test using the statistic software program SPSS (SPSS Inc., Chicago, Illinois, USA).

\section{Results and Discussion}

The difference in mean values of cervical mucus amylase between two groups was significantly ( $\mathrm{P}$ $<0.01$ ) higher in normal as compared to repeat breeder animals. However, Wagh and Hukeri, [5] reported no significant difference between two groups which is contradictory to present finding. Serum amylase activity did not statistically differ between groups. Tsiligianni et al. [6] documented cervical mucus amylase activity in spontaneous and induced estrus in Friesian cattle with no significant difference between these groups despite the fact that cervical mucus in the induced estrus groups was thicker which indicates that water content in the cervical mucus does not influence amylase activity. Cervical mucus amylase concentration was significantly higher in normal compared to repeat breeder animals showing important role in fertility and was in accordance with the findings of O'Hagan et al. [7] that addition of amylase in bull semen dilutors improve conception rate in cattle. Similar successful attempts have been made to improve sperm transport by adding compounds such as amylases and glucosidases to bull semen diluents and fertility improved significantly [8]. According to Hawk, [9] mostly failure of fertilization occur due to failure of sperm ova contact rather than from unfertilizability of gametes. Amylase is involved in making proper channel in cervical mucus for sperm transport by hydrolysis of linkage of large polysaccharides composed of glycogen and making reducing sugars available for cleavage. Lactate and pyruvate are important substrate for sustaining spermatozoa metabolism during their transit through reproductive tract [10]. Amylase significantly increases the lactate production of rabbit sperm in vitro and beneficial for maintenance of sperm motility indicating vital role of 
amylase in fertility. The improvement in conception rates by addition of $\alpha$ or $\beta$ amylase to bull semen diluents [11] implicated that these enzymes may be involved in capacitation of bull sperm [5]. It has been suggested that presence of $\alpha$-amylase in the cervical mucus of women and cattle play an important role in sperm capacitation [12]. Results of present study are in agreement with these findings as the higher cervical mucus amylase concentration in normal cattle with higher conception rate compared to repeat breeder animals, also indicate role of amylase in fertility. Calcium and cAMP signaling are proposed to act at different steps in amylase release. The combination of isoproterenol and substance $\mathrm{P}$ evokes biphasic amylase release and the amount of released amylase is greater than that induced by each agonist alone in parotid acinar cells [13]. The same mechanism possibly holds well in cervical mucus amylase secretion too and should be studied further for confirmation.

\section{Conclusion}

It can be concluded from present study that cervical mucus amylase could be a facilitator of sperm transport and capacitation process in female genital tract leading to acceptable fertility in normal animals. However, repeat breeder deficient in amylase could be supplemented with the same in the form of semen additive at time of AI or by some other means in order to settle them down, requiring further investigations.

\section{Author's Contribution}

Ashok kumar collected sample in LPM dairy and done processing in nuclear research laboratory and drafted the manuscript. S Mehrotra guided the study and help in drafting of manuscript. SS Dangi processed samples in nuclear research laboratory. G Singh guided during the research. Mahak Singh and AS Mahla helped in collection of samples in dairy. All authors read and approved the final manuscript.

\section{Acknowledgements}

Authors sincerely thank Director, IVRI, Incharge LPM, Head of Animal Reproduction Division, ICAR for facilities provided and financial support.

\section{Competing interest}

Authors declare that they have no competing interest.

\section{References}

1. Schumacher, G.F.B. (1970). Biochemistry of cervical mucus. Fertility and Sterility., 21: 697-700.

2. Linford, E. (1974). Cervical mucus: an agent or barrier to conception? J. Reprod. Fertility., 37: 239-250.

3. Treves, C., Vincenzini, M. T., Vanni, P., Bardazzi, F., Cattaneo, A. and Ogier, E. (1986). Changes in enzyme levels in human cervical mucus during the menstrual cycle. Internation. J. Fertility., 31:59-66.

4. Prasad, A., Kalalyan, N.R., Bachlaus, N.K., Arora, R.C. and Pandey, R.S. (1981). Biochemical changes in the cervical mucus of buffalo after induction of oestrus with prostaglandin $\mathrm{F} 2$ alpha and cloprostenol. J. Reprod. Fertility., 62: 583-587.

5. Wagh, A.J. and Hukeri, V.B. (1990). Study on Amylase enzyme of cervical mucus of crossbred cows in relation to fertility. Indian J.Anim. Reprod., 11:62-63.

6. Tsiligianni, T. H., Karagiannidis, A., Saratsis, P. H. and Brikas, P. (2003). Enzyme activity in bovine cervical mucus during spontaneous and induced estrus. Canadian J. Vet. Res., 67:189-193.

7. O'Hagan, C., Linford, E., Lawton, F., Stewart, D. L. and Westgarth, D. R. (1974). The influence of beta-amylase and beta-glucuronidase on fertility of frozen bull semen. Brt. Vet. J., 130:292.

8. Hafs, H. D., Boyd, L. J., Johnson, W. J. and Hunter, A. G. (1971). Fertility of bull semen with added betaglucuronidase. J. Dairy Sci., 54: 420.

9. Hawk, H. W. (1987). Transport and fate of spermatozoa after insemination of cattle. J. Dairy Sci., 70: 1487-1503.

10. Murdoch, R.N. and White, I.G. (1966). Metabolism of glucose, fructose, acetate, lactate and pyruvate by ram, bull, dog and rabbit spermatozoa. J. Reprod. Fertilit.y, 12: 271.

11. Kirton, K.T., Boyd, L.J. and Hafs, H.D. (1968). Fertility of bull semen with added amylase. J. Dairy Sci., 51: 1426.

12. Benbia, S. Kalla, A., Yahia, M., Belhadi, K. and A. Zidani (2011). Enzymes Activity in Bovine Cervical Mucus Related to the Time of Ovulation and insemination. World Academy of Science, Engineering and Technology, 59: 670-672.

13. Seino, S. and Shibasaki, T. (2005). PKA-Dependent and PKA-Independent Pathways for cAMPRegulated Exocytosis. Physiol. Rev. 85: 1303-1342.

\section{$* * * * * * * *$}

